\title{
Review and Recalculation of Growth and Nucleation Kinetics for Calcite, Vaterite and Amorphous Calcium Carbonate
}

\author{
Luke Bergwerff $^{1}$ and Leon A. van Paassen ${ }^{2, *}$ \\ 1 Faculty of Civil Engineering and Geosciences, Delft University of Technology, Stevinweg 1, \\ 2628 CN Delft, The Netherlands; lukebergwerff@gmail.com \\ 2 School of Sustainable Engineering and the Built Environment, Arizona State University, 650 E Tyler Mall, \\ Tempe, AZ 85287-3005, USA \\ * Correspondence: leon.vanpaassen@asu.edu
}

Citation: Bergwerff, L.;

van Paassen, L.A. Review and

Recalculation of Growth and

Nucleation Kinetics for Calcite, Vaterite and Amorphous Calcium Carbonate. Crystals 2021, 11, 1318 . https://doi.org/

$10.3390 /$ cryst11111318

Academic Editor: Linda Pastero

Received: 22 July 2021

Accepted: 20 October 2021

Published: 28 October 2021

Publisher's Note: MDPI stays neutral with regard to jurisdictional claims in published maps and institutional affiliations.

Copyright: (c) 2021 by the authors. Licensee MDPI, Basel, Switzerland. This article is an open access article distributed under the terms and conditions of the Creative Commons Attribution (CC BY) license (https:// creativecommons.org/licenses/by/ $4.0 /)$.

\begin{abstract}
The precipitation of calcium carbonate is well studied in many fields of research and industry. Despite the fact that, or perhaps because of the fact that, it is well studied in many fields, different approaches have been used to describe the kinetics of the precipitation process. The aim of this study was to collect and compare the data available in the literature and find a consistent method to describe the kinetics of growth and nucleation of the various polymorphs of calcium carbonate. Inventory of the available data showed that a significant number of the literature sources were incomplete in providing the required information to recalculate the kinetic constants. Using a unified method, we obtained a unique set of parameters to describe the kinetics for growth for calcite, vaterite and amorphous calcium carbonate (ACC) and nucleation for vaterite and ACC. Recalculation of the kinetic constants demonstrated that calcite confirmed there are two growth mechanisms within one polymorph, namely pure spiral growth and spiral growth mixed with surface nucleation. The spiral growth does not show second-order growth, which is typically attributed to it. Re-evaluation of the available nucleation data confirmed the suggested existence of a second pure ACC polymorph with a solubility product between $10^{-5.87}$ and $10^{-5.51} \mathrm{~mol}^{2} \mathrm{~kg}_{\mathrm{w}}{ }^{-2}$.
\end{abstract}

Keywords: crystal growth; crystal nucleation; kinetics; vaterite; calcite; amorphous calcium carbonate

\section{Introduction}

Calcium carbonate precipitation is a widespread phenomenon and a relevant topic for many fields of research and industry. Theories have been developed to describe the growth and nucleation kinetics of calcium carbonate minerals that may be used to determine the size, shape and number of crystals for a given solution composition and environmental conditions. Because calcium carbonate precipitation is such a prevalent phenomenon, much of the literature is dedicated to the kinetics of calcium carbonate precipitation. However, despite, or perhaps because of, the vast amount of the literature available, various approaches have been used to describe the kinetics and determine the kinetic constants, which may lead to inconsistencies when comparing the different datasets and make it difficult to develop a unified approach which fits all available data. It may very well be possible that the relevance to the different fields has contributed to the wide variety of approaches. The fact that calcium carbonate crystals have multiple polymorphs complicates the already abstruse situation even further.

Inconsistencies in the literature can have multiple sources. The first source is an inconsistent use of definitions. For example, the (super-)saturation, $S$, which is at the core of any theory on mineral precipitation kinetics, is not always used consistently. Although the definition of saturation is, in most cases, the same, the way saturation is used in the equations varies significantly depending on the application or research field. Saturation and supersaturation are used interchangeably, and sometimes supersaturation index is used. It is not always clear which polymorph is referred to, and supersaturation is often 
confused with a driving force (e.g., $\ln (S),\left(c-c^{*}\right)$ or $\left.(\sqrt{ } S-1)\right)$. Another example leading to errors is the ambiguous usage of the mathematical operator "log". It is not always clear when results are plotted on a logarithmic scale whether " $\log 10$ " or "ln" is meant (e.g., in [1-3]). We will discuss definitions in the methods section.

The second source of inconsistencies is the methodology to calculate saturation. Solutions containing calcium and dissolved inorganic carbon tend to form complexes, and it is therefore important to take ion speciation into account. Additionally, activity corrections are required to account for the non-ideal behavior of aqueous solutions. The calculation of speciation and activity corrections depend on each other in a non-linear way and are subject to many considerations. For speciation calculations, the concentrations of ions and ion complexes that are very small are sometimes neglected. For activity corrections, many different methods are available, such as the extended Debye-Hückel method, the Davies method, the specific ion interaction theory (SIT) and the Pitzer equations, among many others. These methods always have a limited application for a specific range of ionic strengths of the solution and sometimes a limited validity for the amount or valency of ions present in solution. Both the limited application of activity correction methods and the occurrence of certain ion complexations are not always considered and may lead to significant deviations in the calculated saturation and consequent precipitation kinetics.

The third source of inconsistencies is related to variations, errors and omissions in the reported experimental procedures that limit the interpretation and reproducibility of published results. In some cases, methods are not always clearly described, and units or values of required parameters are not always provided (e.g., [4,5]). It is not always possible to reproduce solutions from a materials section when they are not described completely or accurately.

These kinds of inconsistencies may not be a problem for a single study dealing with growth or nucleation of a single polymorph only. However, they make it difficult to check or reproduce the results and can result in significant variations when trying to combine the results of various studies, as we demonstrate here in this review.

This study aimed to review the available data in the literature describing the kinetics for growth and nucleation of calcium carbonate and develop a unified approach to compare all available datasets. The study was performed based on observations during experimental studies on Microbially Induced Carbonate Precipitation (MICP) by urea hydrolysis, which showed that size, shape, and type of the calcium carbonate crystals varied significantly depending on the hydrolysis rate and available surface area for crystal growth [6,7]. Based on Scanning Electron Microscope (SEM) and X-ray Diffraction (XRD) analysis, three different polymorphs were identified: calcite, vaterite and amorphous calcium carbonate (ACC). Other polymorphs (aragonite, ikaite and calcium carbonate monohydrate) were not included in the study, as these were not observed in the experiments and are considered uncommon in freshwater environments or at the relevant temperature range [8,9]. We used all relevant data in the literature that we could find, as well as the reported solution compositions and equations from the Theory section described below, to recalculate saturation values in a single consistent manner, so that all data could be compared with each other. The resulting saturation data were used to determine growth and nucleation parameters for calcite, vaterite and amorphous calcium carbonate (ACC). The kinetic parameters obtained in this way will enable us to describe the crystal precipitation kinetics consistently, as long as the same definitions and methods are used.

\section{Theory}

In this section, we present the equations and definitions used in this study to recalculate the crystal growth nucleation rates from the solution compositions.

Firstly, the activity of an ion is determined by the following:

$$
a_{i}=\gamma_{i} m_{i}
$$


where $a_{i}$ is the activity of ion $i$ in mol kgw ${ }^{-1}$ ( $\mathrm{kgw}$ is $\mathrm{kg}$ of solution, in this case water), $\gamma_{i}$ is the unitless activity coefficient of ion $i$ and is determined by an activity correction method and $m_{i}$ is the molality of ion $i$ in $\mathrm{mol} \mathrm{kgw}^{-1}$.

The activities of the calcium ions and carbonate ions are then used to calculate the ionic activity product of calcium carbonate to give the saturation for the various polymorphs. The saturation definition [10] used in this study is as follows:

$$
S_{j}=\frac{I A P}{K_{j}}=\frac{\prod a_{i}^{v_{i}}}{K_{j}}
$$

where $S_{j}$ is the saturation of crystal $j, I A P$ is the ionic activity product in $\mathrm{mol}^{v} \mathrm{kgw}^{-v}, K_{j}$ is the equilibrium constant of crystal $j$ in $\mathrm{mol}^{v} \mathrm{kgw}^{-v}$ and $v_{i}$ is the stoichiometry of ion $i$ in the crystal roster of crystal $j$.

In this study, we used the software PhreeqC (version 3.3.8-11728) [11] with the default database to determine the ionic activity products with respect to calcium carbonate of solutions. This software is flexible with the input consisting of varying ion types, which is ideal in comparing different studies. Additionally, the software estimates the conversion of molarities into molalities, and this also helps in comparing different studies. The raw saturation output of PhreeqC is in $\log 10(S)$ instead of the saturation shown in Equation (2).

It is imperative to calculate the ionic activity product correctly for crystals with multiple polymorphs, such as calcium carbonate. When the ionic activity product increases enough, a less stable polymorph that grows and nucleates faster will take over. Given time, these less stable polymorphs will transform in a more stable polymorph, through a process referred to as Ostwald ripening [12]. The polymorphs considered in this study are in order of decreasing stability calcite, vaterite and amorphous calcium carbonate (ACC).

A general crystal growth equation for a crystal with two types of ions was derived [13].

$$
\frac{\partial m_{c}}{\partial t}=k A_{c}\left(S^{\frac{1}{v}}-1\right)^{g} \quad S \geq 1
$$

where $m_{c}$ is the crystal mass in mol, $t$ is time in $\mathrm{s}, k$ is a growth rate constant in $\mathrm{mol} \mathrm{m}^{-2} \mathrm{~s}^{-1}$, $A_{c}$ is the available crystal surface for growth in $\mathrm{m}^{2}, v$ is the total mol of ions per mol of crystal and $g$ is a unitless growth order parameter.

According to Davies, $g$, the unitless growth order, was derived to be equal to $v$. However, later it was found that $g$ could also have a different value depending on the type of growth mechanism [14]. Equation (3) is a bulk growth description. Another possibility is to study the growth of individual crystals. In such a case, the crystal-face growth speed is used:

$$
\frac{\partial r_{c}}{\partial t}=k_{r}\left(S^{\frac{1}{v}}-1\right)^{g} \quad S \geq 1
$$

where $r_{c}$ is the crystal radius in $\mathrm{m}$, and $k_{r}$ is the growth constant in $\mathrm{m} \mathrm{s}^{-1}$. The bulk growth rate and the individual growth rate are directly related to each other if the bulk growth rate is used for crystals of uniform size and shape. In this case, they are correlated by the following:

$$
k_{r}=\frac{A_{f}}{3 V_{m} V_{f}} k
$$

where $A_{f}$ and $V_{f}$ are unitless shape factors, and $V_{m}$ is the inverse molar volume in $\mathrm{mol} \mathrm{m}^{-3}$. The shape factors depend on the crystal shape and relate the crystal radius to the crystal surface area, $A_{c}$, in $\mathrm{m}^{2}$ and crystal volume, $V_{c}$, in $\mathrm{m}^{3}$. Assuming spherical crystals (which is the most common assumption), $A_{f}$ is $4 \pi$ and $V_{f}$ is $4 / 3 \pi$. For a single crystal, $m_{c}, A_{c}$ and $V_{c}$ can be calculated by using the following:

$$
\begin{aligned}
& A_{c}=A_{f} r_{c}{ }^{2} \\
& V_{c}=V_{f} r_{c}{ }^{3}
\end{aligned}
$$




$$
m_{c}=V_{m} V_{c}
$$

Several nucleation types exist. Nucleation can occur homogeneously by itself or heterogeneously by using other material as nucleation point. Furthermore, nucleation can occur in the solution, the so-called bulk nucleation, or on a surface, the so-called surface nucleation. In this study we consider homogeneous bulk crystal nucleation rates. The most common equation to describe the nucleation rate found in the literature is as follows:

$$
J=A_{n} \exp \left(-\frac{B_{n}}{\ln ^{2}(S)}\right) \quad S \geq 1
$$

where $J$ is the nucleation rate in $\mathrm{m}^{-3} \mathrm{~s}^{-1}, A_{n}$ is a rate constant in $\mathrm{m}^{-3} \mathrm{~s}^{-1}$ and $B_{n}$ is a unitless constant related to the nucleation energy barrier. The nucleation parameters $A_{n}$ and $B_{n}$ were theoretically derived and given by Kashchiev [10]. He also demonstrated that the nucleation rate differs for a diffusion limited nucleation and kinetically limited nucleation, which could be described by using the following:

$$
\begin{array}{ll}
J=A_{n}^{\text {diff }} \operatorname{Sln} S \exp \left(-\frac{B_{n}}{\ln ^{2}(S)}\right) & S \geq 1 \\
J=A_{n}^{k i n} \operatorname{sexp}\left(-\frac{B_{n}}{\ln ^{2}(S)}\right) & S \geq 1
\end{array}
$$

in which constants $A_{n}^{\text {diff }}, A_{n}^{\text {kin }}$ and $B_{n}$ are calculated by following Equations (12)-(14). We have updated these equations from Kaschiev [10] to incorporate the shape factors of Equations (6) and (7). It is important to realize that nuclei are likely to have different properties (e.g., shape and density) as matured crystals. Nevertheless, some assumptions about these properties must be made to have a working description of the mechanics:

$$
\begin{gathered}
A_{n}^{\text {diff }}=\frac{1}{2 \sqrt{\pi}} \sqrt{A_{f}} D V_{m} N_{A}^{2} K^{\frac{1}{v}} \sqrt{\frac{k_{b} T}{\gamma}} \\
A_{n}^{k i n}=\left(\frac{1}{162 \sqrt{\pi}}\right)^{\frac{1}{3}} \frac{A_{f}^{\frac{3}{2}}}{V_{f}} D V_{m}^{\frac{1}{3}} N_{A^{\frac{4}{3}}} K^{\frac{1}{v}} \sqrt{\frac{\gamma}{k_{b} T}} \\
B_{n}=\frac{4}{27} \frac{A_{f}^{3}}{V_{f}^{2}} \frac{1}{\left(V_{m} N_{A}\right)^{2}} \frac{\gamma^{3}}{\left(k_{b} T\right)^{2}}
\end{gathered}
$$

where $D$ is a diffusion constant in $\mathrm{m}^{2} \mathrm{~s}^{-1}, N_{A}$ is the Avogadro constant in $\mathrm{mol}^{-1}, k_{b}$ is the Boltzmann constant in $\mathrm{J} \mathrm{K}^{-1}, T$ is the temperature in $\mathrm{K}$ and $\gamma$ is the specific surface energy of the crystal in $\mathrm{J} \mathrm{m}^{-2}$.

Most studies investigating nucleation phenomena focus on the induction time. The induction time is the time between when the solution becomes oversaturated and the time of the first nucleus appearing. These nuclei are very small and are therefore hard to detect. Depending on the detection method of the experiment, nuclei may need to grow before being able to be detected. This can lead to a significant variability in the experimentally determined and reported induction times.

The induction time depends not only on the saturation of the solution, but also on the volume of the solution. The classical nucleation theory describes the chance that a nucleus larger than a critical nucleus appears and starts growing. This means that, for more molecules present in the solution, this is likely to happen sooner. Therefore, if the volume increases while the concentrations remain the same, the induction time becomes shorter.

While the induction time is mostly reported, the dependency on the volume makes it difficult to directly compare studies. Therefore, we will use the nucleation rate, which gives the rate per volume, rather than induction times. To obtain the nucleation rate from studies which reported induction times, the reported induction times needed to be converted to 
nucleation rates. The induction time equals an expected amount of nuclei of exactly one. Therefore, the relation becomes the following:

$$
J=\frac{1}{V \tau_{\text {ind }}}
$$

where $V$ is the solution volume in $\mathrm{m}^{3}$, and $\tau_{\text {ind }}$ is the induction time in $\mathrm{s}$.

Another process in crystal development is dissolution. When a crystal is in a solution that is unsaturated, it will dissolve. The rate of dissolution requires different parameters than growth. For a polymorphic crystal such as calcium carbonate, the balance of growth and dissolution leads to the crystal mass eventually transforming from a less stable polymorph into the most stable phase. This process is called Ostwald ripening and was placed outside the scope of this study.

\section{Results and Discussion}

\subsection{Recalculating Saturation Values}

Growth parameters, nucleation parameters and equilibrium constants all depend on temperature and pressure. Therefore, only the literature data were used that originate from experiments performed at $25{ }^{\circ} \mathrm{C}$ and atmospheric pressure, unless stated otherwise. We used the software PhreeqC (version 3.3.8-11728) [11] with the default database to determine the ionic activity products and compare them with the solubility products of the various calcium carbonate polymorphs. This software is flexible, with the input consisting of varying ion types, and this is ideal when comparing different studies. Additionally, the software converts molarities into molalities, and this also helped us compare the different studies. The saturation output of PhreeqC is in $\log 10(S)$ instead of the saturation shown in Equation (1).

\subsection{Kinetics of Growth}

Reported growth rate constants for calcite and vaterite (Table 1) cover a broad range of values and units depending on the definitions and experimental conditions used [1,4,5,15-33]. The growth order, $\mathrm{g}$, for calcite varies between 0.91 and 4.71 in these publications. Additionally, several parameters for alternative growth models [34-36] are reported. The growth order, g, for vaterite varies between 2 and 2.02 in these publications. For both calcite and vaterite, some of these parameters are reported to depend on ionic strength, ratio of calcium and carbonate or $\mathrm{pH}$ (e.g., in $[28,30,36])$.

Some of the variation in reported parameters can be explained by the usage of different definitions, units and driving forces in the different publications. However, even when the rate constants are recalculated by using the same definitions and units, the values of the parameters can vary by multiple orders of magnitude from each other. Hence, there is a need to investigate the cause of these variations in order to obtain single unified parameters.

However, the observations in attempting to unify the data from many publications are striking. Firstly, there is a large amount of papers where reported growth rates cannot be correlated to solution compositions $[1,18,23-27,29,32-35,37-40]$. The correlation was not possible because either the solution composition was not defined clearly enough, the growth rates was not reported clearly, the saturation calculation was not reported clearly enough, the specific surface of the crystals was not measured or reported, or the solution was bubbled with $\mathrm{CO}_{2}$ so that the actual carbonate concentration is hard to determine exactly.

Secondly, a large number of publications that studied calcite growth in calcite seeded experiments used solutions that were either all oversaturated for vaterite $[2,3,19,21,41-50]$ or a part of the solutions used that were oversaturated for vaterite $[15,22,28,51,52]$. When a solution is oversaturated for vaterite, vaterite growth is preferred over calcite growth, as we show in this paper. This means that most results from these papers that specifically study calcite are moot. 
Table 1. Reported growth rate constants in the literature.

\begin{tabular}{|c|c|c|c|}
\hline Polymorph & Growth Rate Constant & Unit & Reference \\
\hline \multirow{16}{*}{ Calcite } & $4.0-8.8$ & $\mathrm{~L} \mathrm{~mol}^{-1} \mathrm{~s}^{-1}\left(\mathrm{~g}_{\text {seed }} \mathrm{L}^{-1}\right)^{-1}$ & {$[4,15]$} \\
\hline & $6.48 \times 10^{4}$ & $\mathrm{~L}^{2} \mathrm{~mol}^{-1} \mathrm{~m}^{-2} \mathrm{~s}^{-1}$ & [25] \\
\hline & $1.43 \times 10^{-10}-1.08 \times 10^{-9}$ & $\mathrm{~mol} \mathrm{~m}^{-2} \mathrm{~s}^{-1}$ & {$[16,17]$} \\
\hline & $5.37 \times 10^{-7}-2.34 \times 10^{-6}$ & $\mathrm{~mol} \mathrm{~m}^{-2} \mathrm{~s}^{-1}$ & [18] \\
\hline & $2.91 \times 10^{-9}-1.39 \times 10^{-6}$ & $\mathrm{~mol} \mathrm{~m}{ }^{-2} \mathrm{~s}^{-1}$ & [1] \\
\hline & $1.64 \times 10^{-7}-2.81 \times 10^{-7}$ & $\mathrm{~mol} \mathrm{~m}^{-2} \mathrm{~s}^{-1}$ & [19] \\
\hline & $2.21 \times 10^{-8}-7.48 \times 10^{-4}$ & $\mathrm{~mol} \mathrm{~m}^{-2} \mathrm{~s}^{-1}$ & [24] \\
\hline & $3.42 \times 10^{-7}$ & $\mathrm{~mol} \mathrm{~m}^{-2} \mathrm{~s}^{-1}$ & [26] \\
\hline & $6.64 \times 10^{-8}-7.80 \times 10^{-7}$ & $\mathrm{~mol} \mathrm{~m}^{-2} \mathrm{~s}^{-1}$ & [27] \\
\hline & $5.8 \times 10^{-7}-3.35 \times 10^{-6}$ & $\mathrm{~mol} \mathrm{~m} \mathrm{~m}^{-2} \mathrm{~s}^{-1}$ & [28] \\
\hline & $8.56 \times 10^{-8}-2.65 \times 10^{-7}$ & $\mathrm{~mol} \mathrm{~m}{ }^{-2} \mathrm{~s}^{-1} \mathrm{~kg}_{\mathrm{w}}{ }^{-1}$ & [23] \\
\hline & $4.05 \times 10^{-11}-1.98 \times 10^{-10}$ & $\mathrm{~m} \mathrm{~s}^{-1}$ & [20] \\
\hline & $5.0 \times 10^{-10}$ & $\mathrm{~m} \mathrm{~s}^{-1}$ & [21] \\
\hline & $1.1 \times 10^{-10}$ & $\mathrm{~m} \mathrm{~s}^{-1}$ & [22] \\
\hline & $1.13 \times 10^{-10}-9.2 \times 10^{-10}$ & $\mathrm{~m} \mathrm{~s}^{-1}$ & [6] \\
\hline & $8.08 \times 10^{-26}$ & $\mathrm{~m}^{3} \mathrm{~s}^{-1}$ & [29] \\
\hline \multirow{4}{*}{ Vaterite } & $5.60 \times 10^{-10}-6.10 \times 10^{-10}$ & $\mathrm{~m} \mathrm{~s}^{-1}$ & [30] \\
\hline & $1.06-1.17 \times 10^{-10}$ & $\mathrm{~m} \mathrm{~s}^{-1}$ & [31] \\
\hline & $1.71 \times 10^{-9}$ & $\mathrm{~m} \mathrm{~s}^{-1}$ & [32] \\
\hline & $5.27 \times 10^{-10}$ & $\mathrm{~m} \mathrm{~s}^{-1}$ & [33] \\
\hline
\end{tabular}

Luckily, several studies remained that contained at least one useful point of data where the solution composition could be correlated with the growth rate (shown in Figure 1) in which the growth rate is plotted against a recalculated ionic activity product for calcium carbonate $[15,22,28,30,31,51-53]$.

When comparing all reported growth rate data, we found that there is not a clear direct correlation between the ionic activity product and the reported growth rates. Therefore, we took a critical look at the methodologies and environmental conditions that resulted in these data. These methods and conditions are summarized in Table 2.

Firstly, three studies $[22,28,52]$ allowed or expedited the transfer of gaseous $\mathrm{CO}_{2}$ into the solutions. In the case of gaseous $\mathrm{CO}_{2}$ transfer, it is difficult to determine the exact carbonate concentration, as the $\mathrm{pCO}_{2}$ and gas transfer rate may vary depending on bubble size and mass transfer coefficients. Because there was not enough information to backcalculate the $\mathrm{pCO}_{2}$ and gas transfer rate, and because the data of these publications show higher rates than the data from other publications, it is assumed that the actual carbonate concentration and consequent $I A P$ in these experiments were higher than reported. As a result, the data points from these publications should be shifted to the right in Figure 1. Based on this uncertainty, the data from these studies were not used to recalculate the kinetic parameters.

Lastly, the data of Spanos [31] were disregarded, since, in this study, the specific surface area of the crystals could not be recalculated. The specific surface area used in the calculation of these growth rates was considered equal in seeded and unseeded experiment, and this outcome is implausible. Newly formed nuclei have a specific surface which is orders of magnitude larger than crystal seeds. Therefore, the reported growth rates are expected to vary from the actual growth rates. 
Table 2. Experimental conditions for the selected data points in Figure 1.

\begin{tabular}{|c|c|c|c|c|c|c|c|c|}
\hline & $\begin{array}{c}\text { Nancollas } \\
1971[15]\end{array}$ & $\begin{array}{c}\text { Kralj } \\
1990[30]\end{array}$ & $\begin{array}{c}\text { Van der } \\
\text { Weijden } \\
1997 \text { [22] }\end{array}$ & $\begin{array}{c}\text { Spanos } \\
1998[31]\end{array}$ & $\begin{array}{c}\text { Teng } \\
2000[51]\end{array}$ & $\begin{array}{c}\text { Bracco } \\
2012[52]\end{array}$ & $\begin{array}{c}\text { Van der Weijden } \\
2014[28]\end{array}$ & $\begin{array}{c}\text { Nasser } \\
2015[53]\end{array}$ \\
\hline $\begin{array}{l}\text { Reported } \\
\text { morphology }\end{array}$ & Calcite & Vaterite & Calcite & Vaterite & Calcite & Calcite & Calcite & $\begin{array}{c}\text { Calcite, } \\
\text { Vaterite, } \\
\text { ACC }\end{array}$ \\
\hline $\begin{array}{l}\text { Growth rate } \\
\text { constant }\end{array}$ & $4.0-8.8$ & $\begin{array}{c}5.60-6.10 \times \\
10^{-10}\end{array}$ & $\begin{array}{l}1.1 \times \\
10^{-10}\end{array}$ & $\begin{array}{c}1.06-1.17 \times \\
10^{-10}\end{array}$ & - & - & $\begin{array}{c}5.8 \times 10^{-7}-3.35 \\
\times 10^{-6}\end{array}$ & - \\
\hline Unit & $\begin{array}{l}\mathrm{L} \mathrm{mol}^{-1} \mathrm{~s}^{-1} \\
\left(\mathrm{~g}_{\text {seed }} \mathrm{L}^{-1}\right)^{-1}\end{array}$ & $\mathrm{~m} \mathrm{~s}^{-1}$ & $\mathrm{~m} \mathrm{~s}^{-1}$ & $\mathrm{~m} \mathrm{~s}^{-1}$ & - & - & $\mathrm{mol} \mathrm{m} \mathrm{m}^{-2} \mathrm{~s}^{-1}$ & - \\
\hline $\begin{array}{c}\text { Temperature } \\
\left({ }^{\circ} \mathrm{C}\right)\end{array}$ & 25 & 25 & 22 & 25 & 25 & 25 & 22 & 25 \\
\hline $\mathrm{pH}$ & 8.53 & $9.57-9.85$ & $7.56-8.90$ & $9-10$ & 8.5 & $8.25-9.35$ & $7.56-8.90$ & $7.62-7.84$ \\
\hline $\begin{array}{l}\text { Total calcium } \\
\text { concentration } \\
(\mathrm{mM})\end{array}$ & 0.149 & 2.5 & $0.35-0.97$ & $0.4-2.5$ & $0.16-0.34$ & $0.035-0.82$ & $0.25-0.97$ & $10-50$ \\
\hline $\begin{array}{l}\text { Total carbonate } \\
\text { concentration } \\
(\mathrm{mM})\end{array}$ & 10.1 & 2.5 & $6.4-68$ & $0.4-2.5$ & $5.00-10.1$ & $1.25-20.0$ & $6.4-68$ & $10-50$ \\
\hline $\begin{array}{c}\text { Gaseous } \mathrm{CO}_{2} \\
\text { exchange }\end{array}$ & Unknown & No & Yes & No & No & Yes & Yes & No \\
\hline $\begin{array}{l}\text { Ionic strength } \\
(\mathrm{mM})\end{array}$ & 15.8 & $11.2-317$ & $751-856$ & $1.85-11.6$ & 106-112 & $3.51-22.2$ & $0.75-0.86$ & $38.4-184$ \\
\hline Other ions & $\mathrm{Na}, \mathrm{Cl}$ & $\mathrm{Na}, \mathrm{Cl}$ & $\mathrm{K}, \mathrm{Cl}$ & $\mathrm{Na}, \mathrm{K}, \mathrm{NO}_{3}$ & $\mathrm{Na}, \mathrm{Cl}$ & $\mathrm{Na}, \mathrm{Cl}$ & $\mathrm{K}, \mathrm{Cl}$ & $\mathrm{Na}, \mathrm{Cl}$ \\
\hline
\end{tabular}

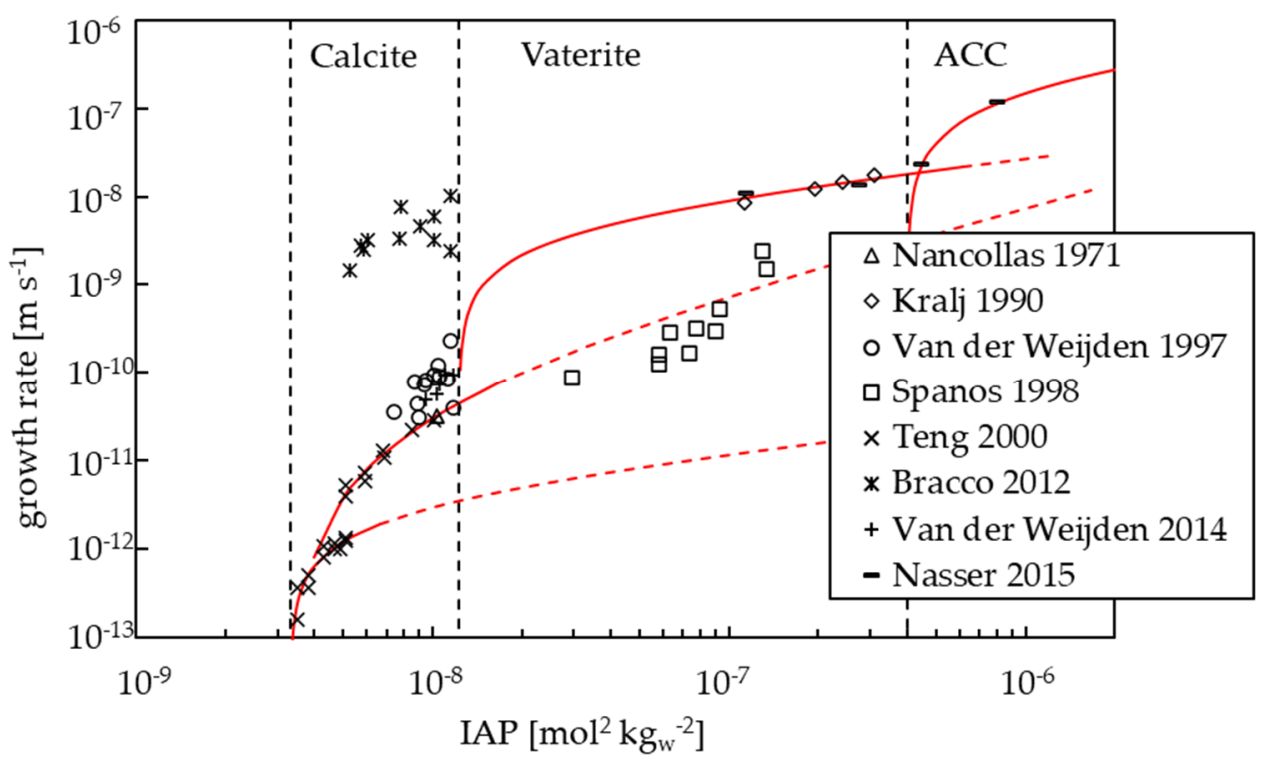

Figure 1. Selected growth data for the three polymorphs of calcium carbonate (from left to right calcite, vaterite and amorphous calcium carbonate (ACC)) plotted against the ionic activity product of calcium carbonate. The data of Nancollas, Kralj, Teng and Nasser were used to fit kinetic parameters, as shown in Figures 2-4. From left to right, the growth types are calcite spiral growth, calcite mixed growth, vaterite growth and ACC growth. As the ionic activity product increases, less stable polymorphs become the dominant growth type. The red lines are the trend lines, which were fitted by using the selected data for each growth mechanism or mineral type, as shown in Figures 2-4. 


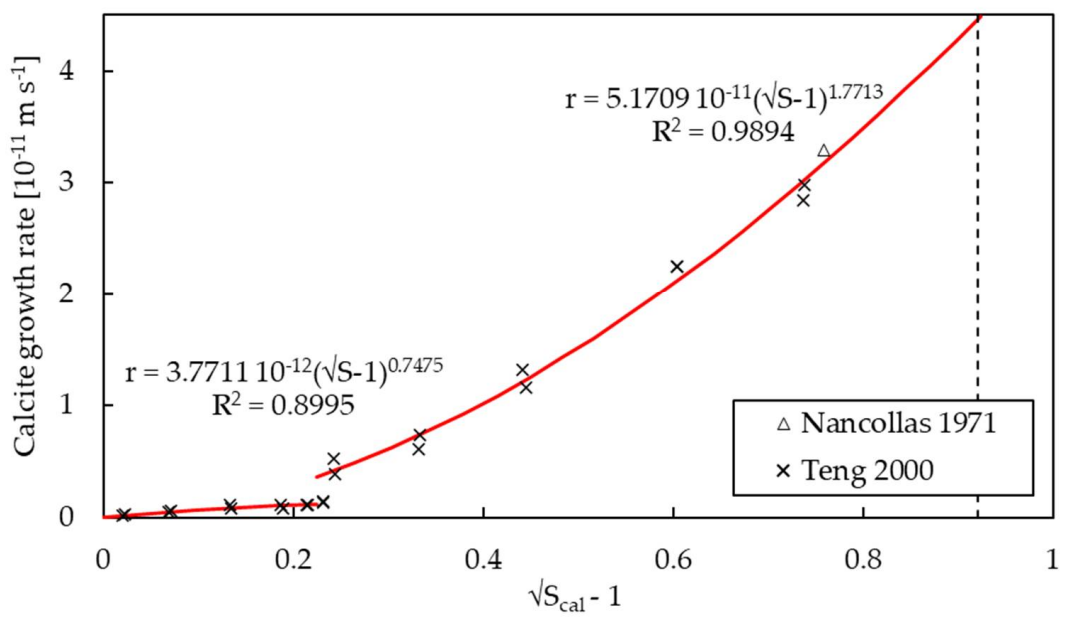

Figure 2. Calcite growth separated in spiral growth $\left(\mathrm{S}_{\mathrm{cal}} \leq 1.514\right)$ and mixed growth $\left(\mathrm{S}_{\mathrm{cal}} \geq 1.549\right)$. The dashed black line indicates where vaterite becomes supersaturated. This gives two sets of parameters, one for each of the different calcite growth mechanisms.

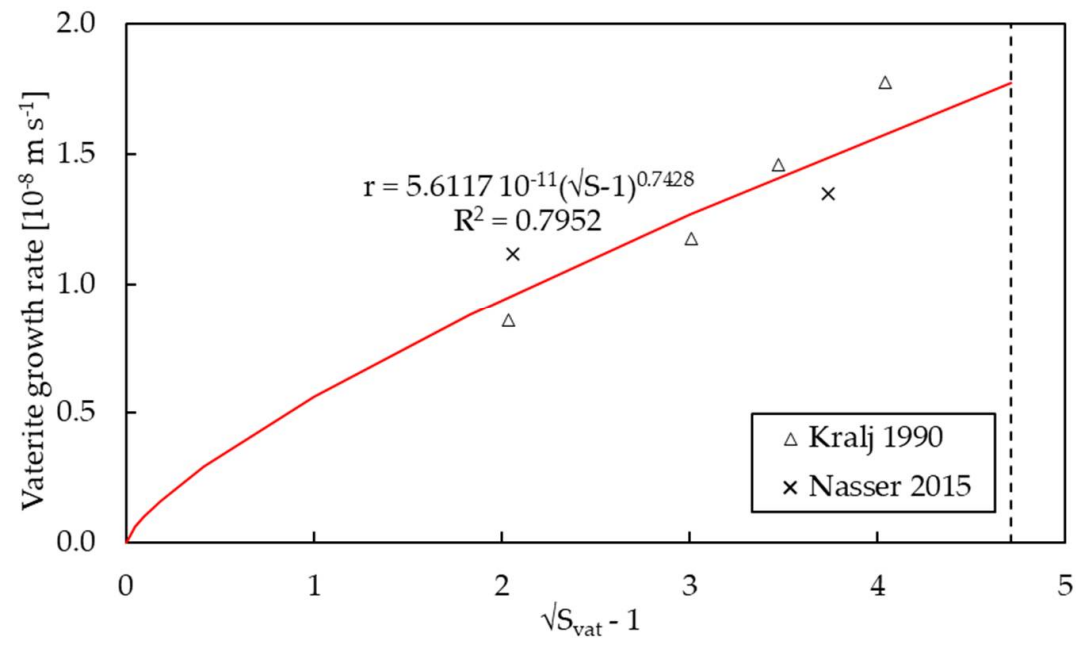

Figure 3. Growth data calculated from Kralj and Nasser, providing a growth rate that is near first order. The dashed line indicates where the supersaturation of ACC starts.

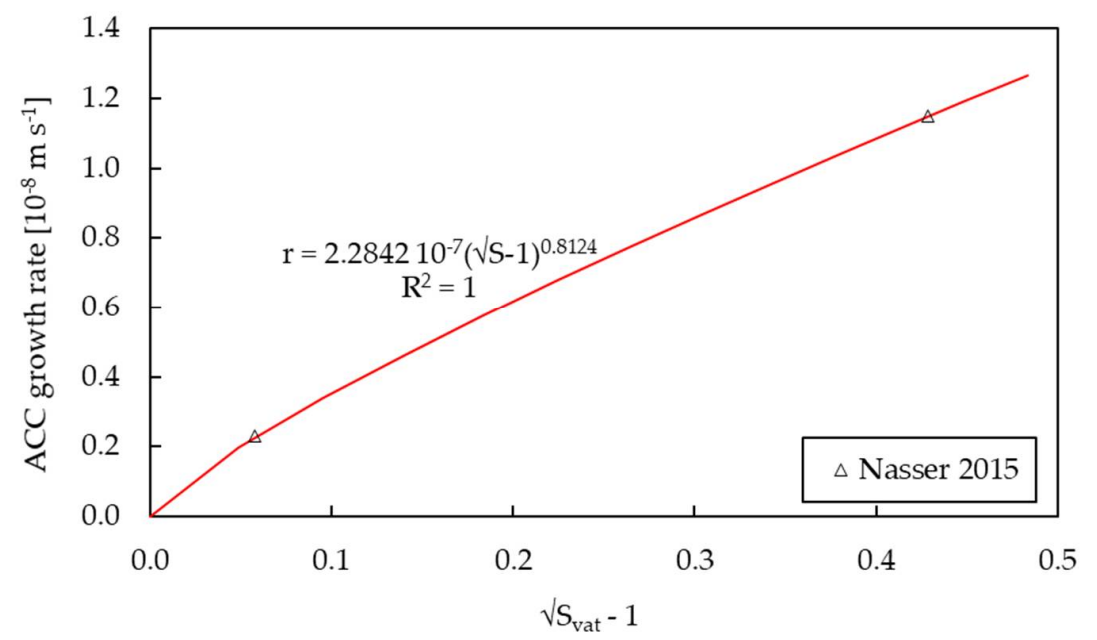

Figure 4. Growth data calculated from Nasser. Because there are only two data points, the calculated parameters should be used carefully. 
The remaining data were used to recalculate the growth-rate constants for each polymorph, starting with calcite. The study that provides the most and most interesting data about calcite growth shows several growth regimes within the calcite polymorph [51]. Using fluid cell atomic force microscopy (AFM), the study demonstrated that, depending on the solution composition, there is either no growth, spiral growth, mixed growth consisting of spiral growth and surface nucleation, or surface nucleation only.

After recalculating the saturation values reported in that study, the solution that showed no growth was undersaturated for calcite, and the solution that showed surface nucleation only was supersaturated for vaterite. The observation that the changes in growth kinetics correspond with the calculated saturations for calcite and vaterite is a strong confirmation that the current method for calculating saturation values is accurate. Fascinatingly, this still gives two growth mechanisms with distinct kinetics within the calcite polymorph, which is visualized in Figure 2.

Interestingly, the spiral growth of calcite at low supersaturation does not show the second-order growth that is typically attributed to calcium carbonate [30,51]. On the other hand, the mixed growth is much closer to a second-order growth. The results also show how important it is to carefully report and design experimental setups and methodologies. While Nancollas [15] only provides one point of data, it strongly agrees with the data of Teng [51].

The growth data for vaterite are provided by Kralj [30] and Nasser [53]. Kralj originally reported the growth constant as a function of ionic strength, but neglected many ionic species for the saturation calculation. Nasser provides data for both the vaterite and the ACC polymorph. Their method continuously keeps track of crystal sizes, providing an appropriate growth rate regardless of polymorph. The results for vaterite are shown in Figure 3, and the data of Nasser, which are the only data available for ACC, are shown in Figure 4.

We found that the kinetic data for the various polymorphs from various studies agree with each other after carefully screening the data and recalculating the saturation values. As these selected datasets vary in terms of concentration ratio, acidity and ionic strength, it can be concluded that these factors do not need to be included in a growth equation. It is worth mentioning that all data used only have sodium and chloride as background electrolytes and that some other electrolytes (e.g., magnesium) or presence of complexing ions or polymers can have an inhibiting effect on calcium carbonate growth $[50,54]$ and therefore do need to be considered when determining the growth kinetics in more complex solutions.

\subsection{Kinetics of Nucleation}

Reported values for all forms of $A_{n}$ in Equations (9)-(11) for unseeded homogeneous nucleation of vaterite or vaterite-calcite mixtures range from $10^{9.45}$ to $10^{36} \mathrm{~m}^{-3} \mathrm{~s}^{-1}[31,38,55]$. Reported values for $B_{n}$ are 12.2 for vaterite [55] and 63.7 for a vaterite-calcite mixture [38]. No nucleation parameters were found for pure calcite and ACC polymorphs. Values reported for the specific surface energy range from 15 to $94 \mathrm{~mJ} \mathrm{~m}^{-2}$ for vaterite $[31,55,56]$ and 41 to $98 \mathrm{~mJ} \mathrm{~m}^{-2}$ for vaterite-calcite mixtures [38,57,58]; and the value is $31 \mathrm{~mJ} \mathrm{~m}^{-2}$ for calcite [59]. Similar to the growth parameters, these parameters have a broad range and are therefore a source of uncertainty in the predicted nucleation rate.

As with the growth kinetics, several publications $[20,58,60,61]$ were disregarded either because the volume of the solution was not reported, or the solution composition was insufficiently described. Fortunately, this leaves plenty of other publications where nucleation rates can be correlated with the solution composition [31,38,42,55-57,59,62]. The experimental conditions and nucleation type are summarized in Table 3. For several of these publications, one of the solute concentrations had to be estimated for a correct $\mathrm{pH}$ or ionic strength, as the experimental conditions were not entirely clear. 
Table 3. Experimental details of studies on the nucleation of calcium carbonate.

\begin{tabular}{|c|c|c|c|c|c|c|c|c|}
\hline & $\begin{array}{l}\text { Söhnel } \\
1978 \text { [57] }\end{array}$ & $\begin{array}{l}\text { Verdoes } \\
1992[55]\end{array}$ & $\begin{array}{l}\text { Gomez- } \\
\text { Morales } \\
1996 \text { [38] }\end{array}$ & $\begin{array}{l}\text { Spanos } \\
1998[31]\end{array}$ & $\begin{array}{l}\text { Mannoli } \\
2000 \text { [42] }\end{array}$ & $\begin{array}{l}\text { Liouliou } \\
2007 \text { [59] }\end{array}$ & $\begin{array}{c}\text { Waly } \\
2012[56]\end{array}$ & $\begin{array}{c}\text { Pochitalkina } \\
2016 \text { [62] }\end{array}$ \\
\hline $\begin{array}{c}\text { Reported } \\
\text { morphology }\end{array}$ & Unspecified & Vaterite & $\begin{array}{c}\text { Vaterite + } \\
\text { Calcite }\end{array}$ & Vaterite & Vaterite & Calcite & $\begin{array}{l}\text { Vaterite + } \\
\text { Calcite }\end{array}$ & Calcite \\
\hline $\begin{array}{c}\text { Working } \\
\text { volume (L) }\end{array}$ & Variable $^{\text {a }}$ & 1.3 & 2 & 0.2 & 0.2 & 0.2 & 2 & 0.3 \\
\hline $\mathrm{pH}$ range & 10.6-10.9 & 10 & $7.8-10$ & $9-10$ & 8.5 & 8.5 & $7.8-8.8$ & 10 \\
\hline $\begin{array}{l}\text { Total calcium } \\
\text { concentration } \\
(\mathrm{mM})\end{array}$ & $3.2-33$ & $0.2-0.5$ & 10 & $0.4-3$ & $4-4.75$ & $3.82-5.48$ & $16.9-23.7$ & $1.1-3.3$ \\
\hline $\begin{array}{l}\text { Total carbonate } \\
\text { concentration } \\
(\mathrm{mM})\end{array}$ & $32-33$ & 28.3 & 10 & $0.4-3$ & $4-4.75$ & $3.82-5.48$ & $3.43-4.80$ & $1.1-3.3$ \\
\hline $\begin{array}{l}\text { Ionic strength } \\
(\mathrm{mM})\end{array}$ & $12.9-106$ & $49.0-49.1$ & $503-507$ & $0.68-11.6$ & $156-184$ & $89.5-93.0$ & $52-1446$ & $157-166$ \\
\hline $\begin{array}{l}\text { Detection } \\
\text { method }\end{array}$ & Conducto-metric & $\begin{array}{c}\mathrm{Ca}^{2+} \\
\text { electrode }\end{array}$ & $\begin{array}{c}\mathrm{pH} \\
\text { measurement }\end{array}$ & $\begin{array}{c}\mathrm{pH} \\
\text { measurement }\end{array}$ & $\begin{array}{c}\mathrm{pH} \\
\text { measurement }\end{array}$ & $\begin{array}{c}\mathrm{pH} \\
\text { measurement }\end{array}$ & $\begin{array}{c}\mathrm{pH} \\
\text { measurement }\end{array}$ & $\begin{array}{c}\text { Laser } \\
\text { optical }\end{array}$ \\
\hline Limitation & diffusion & unknown & kinetic & kinetic & unknown & kinetic & kinetic & kinetic \\
\hline $\begin{array}{l}\text { Other ions } \\
\text { present }\end{array}$ & $\mathrm{Na}, \mathrm{Cl}$ & $\mathrm{Na}, \mathrm{Cl}$ & $\mathrm{K}, \mathrm{Cl}$ & $\mathrm{Na}, \mathrm{NO}_{3}, \mathrm{~K}$ & $\mathrm{Na}, \mathrm{NO}_{3}, \mathrm{~K}$ & $\mathrm{Na}, \mathrm{NO}_{3}, \mathrm{~K}$ & $\mathrm{Na}, \mathrm{Cl}$ & $\mathrm{Na}, \mathrm{Cl}$ \\
\hline
\end{tabular}

a This nucleation experiment was performed in a diffusion-limited scenario; therefore, the "detected" volume depends on the measured induction time.

The induction time that is reported in these studies is visualized in Figure 5. As discussed before, induction times depend on solution volume and are normalized or converted to a nucleation rate according to Equation (16). Following Equation (11), the nucleation parameters for kinetically limited nucleation can then be obtained by linearizing the equation into the following:

$$
\ln \left(\frac{J}{S}\right)=\ln \left(A_{n}^{k i n}\right)-\frac{B_{n}}{\ln ^{2}(S)}
$$

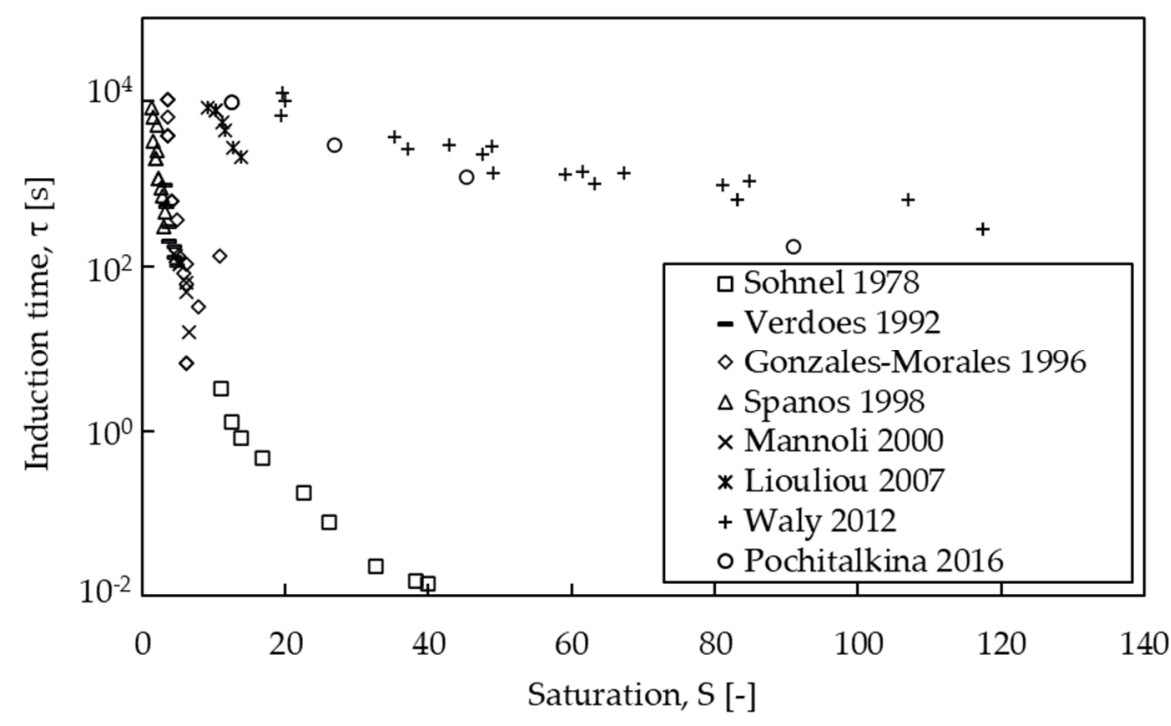

Figure 5. Induction times and saturation values as they are reported in the literature. There seem to be two trends for the data, and no clear correlation between saturation and induction time can be made between different experimental setups.

This relation is plotted in Figure 6, and a linear relation is expected. Indeed, most individual studies show linear behavior, but they do not agree with each other at all, due to the varying saturation calculations and solution volumes in these studies. Figure 7 shows the same data with recalculated saturation values. 


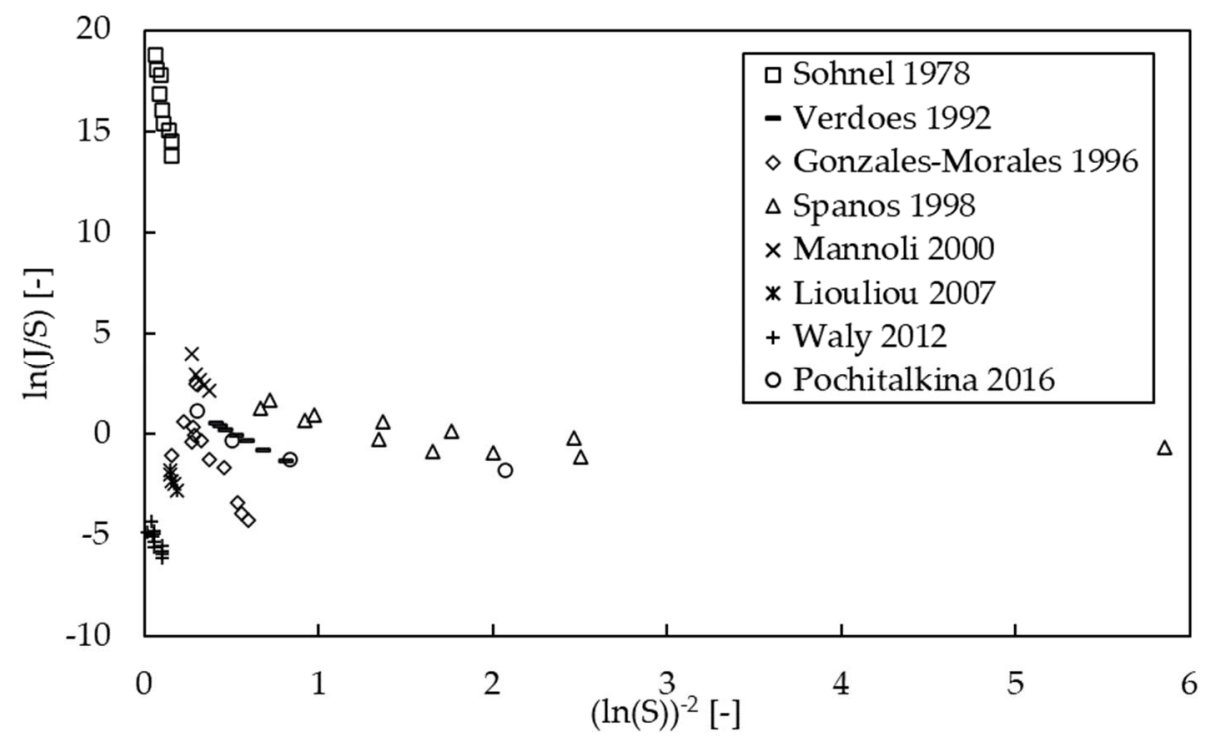

Figure 6. Linearized nucleation rates plotted against saturation values reported in the literature. Linear behavior is expected and shown by most individual studies, but there is no agreement between studies.

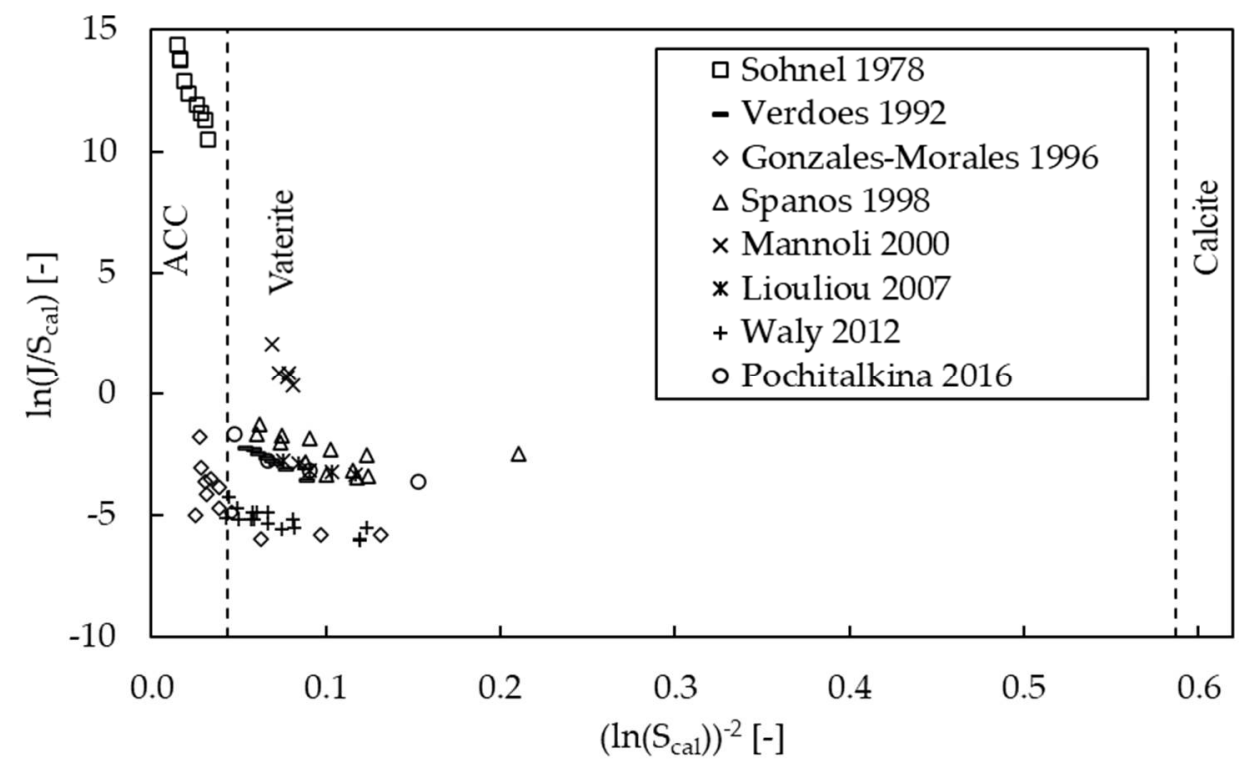

Figure 7. Linearized nucleation rates plotted against the recalculated calcite saturation. Most data are now centered in three groups. One completely in the vaterite regime, one completely in the ACC regime and one group passing over this polymorph change. There are no nucleation data for the calcite regime, although several publications report about calcite nucleation.

The nucleation data in Figure 7 can now be divided into three groups. The group that is completely in the ACC regime [57], the group that is completely in the vaterite regime $[31,42,55,59]$ and the group that is in both regimes $[38,56]$. By recalculating the proper saturation values, it now becomes clear that the nucleation rates reported by Söhnel [57] are so high because he regards the ACC polymorph.

The group that has data for both polymorphs $[38,56]$ does not show such high nucleation rates in the ACC regime. This is likely caused by the detection method used in these studies. The induction time is measured by a pH electrode in the study of Gomez-Morales. Their $\mathrm{pH}$ results show an increasing $\mathrm{pH}$ drift for a significant portion of their experiments. This should not happen after mixing $\mathrm{CaCl}_{2}$ and $\mathrm{K}_{2} \mathrm{CO}_{3}$ solutions. This means that the observed induction times are likely significantly longer than the actual induction times. 
The induction time in the study of Waly is defined as $2 \%$ to $3 \%$ of the total amount of carbonate precipitated. This is significantly more mass than that of a new crystal nucleus, and therefore the nucleation rate is significantly underestimated. These observations may explain why the data of Gomez-Morales and Waly show lower nucleation rates for both polymorphs when compared to the data of other studies.

Most of the vaterite nucleation data $[31,42,55,59,62]$ are grouped together, but they do not entirely agree. Mannoli expedited the transfer of gaseous $\mathrm{CO}_{2}$ into the liquid and shows, similar to the studies that did this for growth, higher rates and should therefore not be considered for determining the nucleation parameters. The induction time in Verdoes was determined with a $\mathrm{Ca}^{2+}$ electrode, which is significantly less sensitive than a $\mathrm{pH}$ electrode, meaning that the measured induction time is likely longer than the actual induction time. Lastly, the data of Spanos are not used for the determination of the parameters. Although the methodology seems fine, the data for growth are significantly different from the other studies, and this holds true for the nucleation data, as well. This leaves three studies with data for the nucleation kinetics $[57,59,62]$.

The remaining nucleation data for vaterite are plotted in Figure 8 as a function of vaterite saturation to obtain the proper trend. One of the data points of Pochitalkina is very close to the ACC regime and is therefore disregarded for the fit, as the classical nucleation theory starts to become less valid for small nuclei sizes. The fit gives values of $0.2820 \mathrm{~m}^{-3} \mathrm{~s}^{-1}$ for $A_{n}{ }^{k i n}$ and 1.8337 for $B_{n}$. By using Equation (13), we obtain a specific surface energy of $16.9 \mathrm{~mJ} \mathrm{~m}^{-2}$ for vaterite, which is within the reported range. Additionally, using Equation (10), the diffusion rate parameter $A_{n}$ diff is predicted to be $0.0208 \mathrm{~m}^{-3} \mathrm{~s}^{-1}$. These values for the $A_{n}$ parameters are in a completely different order of magnitude than the previously reported values, and this is the result of using the proposed method to calculate the saturation values, as well as using nucleation rates instead of induction times.

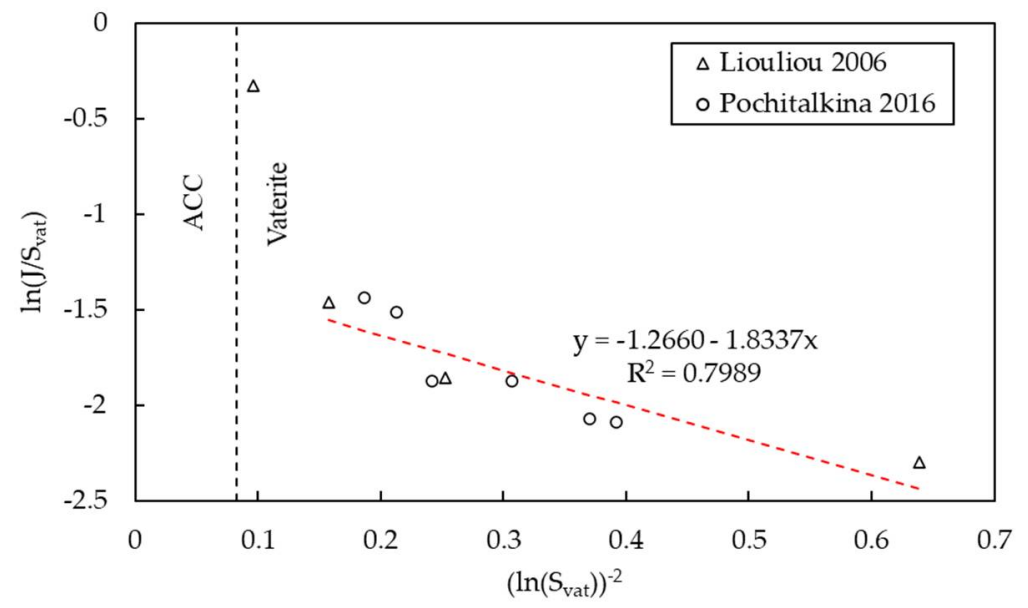

Figure 8. Linearized fit of the kinetically limited nucleation rate for vaterite. The black dashed line indicates where supersaturation for ACC begins. The data point of Pochitalkina close to ACC supersaturation is not used for the fit, as the classical nucleation theory starts to break down for small critical nuclei.

Before plotting the nucleation data of amorphous calcium carbonate (ACC), some consideration to the solubility constant must be given. ACC is an unstable polymorph, thus making it hard to study. Several values for solubility constants of ACC are reported. Two values are reported at $25^{\circ} \mathrm{C}$, namely $10^{-6.40} \mathrm{~mol}^{2} \mathrm{~L}^{-2}$ [63] and $10^{-6} \mathrm{~mol}^{2} \mathrm{~L}^{-2}$ [12]. For an unspecified temperature and without activity corrections, values of $10^{-7.50}$ and $10^{-7.42}$ are reported [64]. Brecivic provides solution compositions and a recalculation with PhreeqC that shows indeed a value of $10^{-6.40} \mathrm{~mol}^{2} \mathrm{~L}^{-2}$ for the equilibrium constant. ACC nucleation kinetic parameters can now be determined by plotting the data of Söhnel [57] with this equilibrium solubility constant, as shown in Figure 9. 


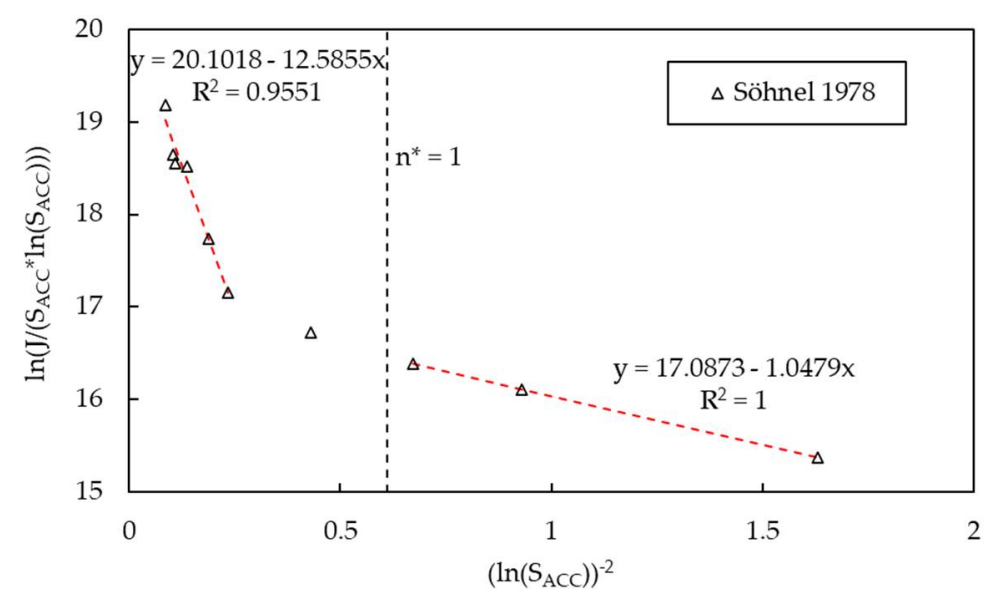

Figure 9. Linearized nucleation data of amorphous calcium carbonate (ACC) assuming diffusion limitation. The data show two linear relations which can be attributed to two separate calcium carbonate nucleation morphologies. The dashed line indicates where the classical nucleation theory predicts a critical nucleus size of one molecule for the first ACC polymorph. This indicates a shift of the solubility constant towards a different polymorph can be expected.

The data in Figure 9 show two linear relations, indicating that the data might include two ACC polymorphs. One possible explanation of the two behaviors is the way the measured volume is approximated. However, even when the volume correction is neglected or exaggerated, the two distinct behaviors remain. Therefore, it is more likely that this behavior can be explained by two different polymorphs. It has been shown that, without additives, there are at least two forms of ACC [65]. Various forms of ACC may have different levels of hydration by including water molecules in the crystal lattice $[66,67]$. This would require an adjustment of the IAP with the water activity. As Söhnel did not discuss the identity of the ACC, we assumed that there is no water in the crystal roster.

The presence of two polymorphs is further substantiated by the calculation of nucleus size following classical nucleation theory. When the critical nucleus size, given by Equation (17) [10], becomes too small, stable nuclei cannot form anymore, and it is likely that another polymorph with higher solubility becomes dominant. The ionic activity product for a critical nucleus size of one molecule is calculated to be $10^{-5.84}$ for ACC, which clearly separates the two polymorphs in Figure 9. This does not mean that the value of the solubility of the second ACC polymorph, which we here call ACC2, equals this value. Realistically, this value lies somewhere in the transition zone and has therefore a value between $10^{-5.87}$ and $10^{-5.51}$ and may change further depending on the degree of hydration of this polymorph.

$$
n^{*}=\left(\frac{2 \gamma A_{f}}{3 k_{b} \operatorname{Tn}^{2} S}\left(V_{f} V_{m} N_{A}\right)^{-\frac{2}{3}}\right)^{3}
$$

where $n^{*}$ is the amount of molecules in a critical nucleus size.

For now, the parameters of both ACC and ACC2 are both determined with the solubility product of ACC. The nucleation rate parameter for diffusion limitation $A_{n}$ diff is $2.64 \times 10^{7} \mathrm{~m}^{-3} \mathrm{~s}^{-1}$, the nucleation parameter $B_{n}$ is 1.0479 and the specific surface energy is $10.2 \mathrm{~mJ} \mathrm{~m}^{-2}$. Alternatively, by using Equation (16), the kinetic rate parameter $A_{n} \mathrm{kin}^{\mathrm{k}}$ is predicted to be $2.96 \times 10^{8} \mathrm{~m}^{-3} \mathrm{~s}^{-1}$. The values for ACC2 are $A_{n}$ diff is $5.37 \times 10^{8} \mathrm{~m}^{-3} \mathrm{~s}^{-1}$ and $B_{n}$ is 12.59 as a function of the solubility constant of ACC.

All the parameters determined in this study were summarized in Table 4. About half of the parameters in this study are based on data from at least two different sources. It is desirable to base all parameters on more data, especially the parameters that are based on very few data points. 
Table 4. Summary of parameters calculated for growth and nucleation Equations (2), (3), (9) and (10) for calcium carbonate polymorphs at $25^{\circ} \mathrm{C}$.

\begin{tabular}{|c|c|c|c|c|c|}
\hline & & Calcite & Vaterite & ACC1 & ACC2 \\
\hline$K$ & $\mathrm{~mol}^{2} \mathrm{~kg}_{\mathrm{w}}{ }^{-2}$ & $10^{-8.48}$ & $10^{-7.913}$ & $10^{-6.40}$ & $10^{-5.87}-10^{-5.51 \mathrm{e}}$ \\
\hline$k$ & $\mathrm{~m} \mathrm{~s}^{-1}$ & $\begin{array}{l}3.7711 \times 10^{-12 a} \\
5.1709 \times 10^{-11 a}\end{array}$ & $5.6117 \times 10^{-9}$ & $2.2842 \times 10^{-7 f}$ & $\mathrm{n} / \mathrm{a}$ \\
\hline g & - & $\begin{array}{l}0.7475^{\mathrm{a}} \\
1.7713^{\mathrm{a}}\end{array}$ & 0.7428 & $0.8124^{f}$ & $\mathrm{n} / \mathrm{a}$ \\
\hline$A_{n}^{k i n}$ & $\mathrm{~m}^{-3} \mathrm{~s}^{-1}$ & $\mathrm{n} / \mathrm{a}$ & 0.282 & $2.96 \times 10^{8 b c}$ & $\mathrm{n} / \mathrm{a}$ \\
\hline$A_{n}^{\text {diff }}$ & $\mathrm{m}^{-3} \mathrm{~s}^{-1}$ & $\mathrm{n} / \mathrm{a}$ & $0.0208^{b}$ & $2.64 \times 10^{7 c}$ & $5.37 \times 10^{8 \mathrm{~cd}}$ \\
\hline$B_{n}$ & - & $\mathrm{n} / \mathrm{a}$ & 1.8337 & $1.0479^{c}$ & $12.59 \mathrm{~cd}$ \\
\hline$\gamma$ & $\mathrm{mJ} \mathrm{m} \mathrm{m}^{-2}$ & $\mathrm{n} / \mathrm{a}$ & 16.9 & $10.2^{c}$ & $\mathrm{n} / \mathrm{a}$ \\
\hline
\end{tabular}

a The first constants are valid for calcite spiral growth up to an IAP of $10^{-8.30} \mathrm{~mol}^{2} \mathrm{~kg}_{\mathrm{w}}{ }^{-2}$. The second constants are valid for mixed growth from an IAP of $10^{-8.29} \mathrm{~mol}^{2} \mathrm{~kg}_{\mathrm{w}}{ }^{-2}$. ${ }^{\mathrm{b}}$ These values are predicted based on theory. ${ }^{\mathrm{c}}$ These values are determined under several assumptions, such as mixing time and detected volume, which may influence the actual values of these parameters. Additionally, these parameters were determined under the assumption that no water molecules are present in the crystal roster. ${ }^{\mathrm{d}}$ These are tentative values based on the solubility of ACC and should be updated when the exact solubility of ACC2 is determined. ${ }^{\mathrm{e}}$ Assuming no water molecules in the crystal roster. ${ }^{\mathrm{f}}$ These parameters were determined with only two data points and are therefore uncertain.

The results from this study show the importance of correctly determining the saturation value, especially to at least determine the correct dominant polymorph for a solution. Many studies work with incorrectly or incompletely reported experimental conditions to study the right polymorph or report the morphology of a different polymorph. This situation is complicated further, as metastable polymorphs can transform into a more stable polymorph (e.g., ACC to vaterite or vaterite into calcite) after they are formed and before the existence of the polymorph is confirmed by, for example, X-ray diffraction.

As a result, several studies try to explain the discrepancies currently in the literature with alternative parameters, such as the calcium-to-carbonate ratio, the $\mathrm{pH}$, or the ionic strength. However, we have shown in this study that the kinetic behavior of the various polymorphs of calcium carbonate can be described correctly by the classical growth and nucleation theory, i.e., if the saturation is calculated correctly and if experiments are conducted with the properly reported, controllable, measurable, and reproducible environmental conditions.

\section{Conclusions}

The aim of this study was to find consistent parameters from the data available in the literature to describe the kinetics of growth and nucleation of the various polymorphs of calcium carbonate.

The amount of and variance in both parameters and methods to study the kinetics of calcium carbonate crystallization currently in the literature are large. While any method can work for a given process or experiment and produce associated parameters, problems arise when combining different processes, such as growth and nucleation, or when comparing data from different sources, as was shown in this study.

When comparing the kinetic data from the different sources, we had to disregard the majority of studies reporting kinetic parameters either because the solution composition and reported rates were not reported clearly enough and could not be correlated to each other or because the experimental setup and methodology could not identify the correct polymorph. After careful screening of the studies and a consistent and meticulous recalculation of saturation values, a set of parameters for growth and nucleation were determined. The newly derived kinetic parameters identified various growth and nucleation mechanisms and allowed us to predict the correct rates and polymorphs for designing processes and experiments. 
Growth parameters were determined for the calcite, vaterite and amorphous calcium carbonate (ACC) polymorphs. Within the calcite polymorph, two different growth mechanisms were identified, namely the spiral growth mechanism and the mixed growth mechanism, consisting of both spiral growth and surface nucleation. Interestingly, the spiral growth was not second order, even though being second order is typically attributed to it.

In the nucleation kinetics, a second amorphous calcium carbonate polymorph was found, with a recalculated solubility constant between $10^{-5.87}$ and $10^{-5.51} \mathrm{~mol}^{2} \mathrm{~kg}_{\mathrm{w}}{ }^{-2}$, but these values should be adapted for the correct level of hydration of this polymorph. The parameters for the nucleation, as well as the specific surface energy of vaterite and amorphous calcium carbonate, were determined.

Author Contributions: Conceptualization, methodology, formal analysis, investigation, writingoriginal draft preparation and visualization, L.B.; writing — review and editing, supervision, project administration and funding acquisition, L.A.v.P. All authors have read and agreed to the published version of the manuscript.

Funding: This research was funded by the Dutch Ministry of Economic Affairs, through 'STW perspectief' program BioGeoCivil, under the project BioFix: Bio-mediated ground improvement to mitigate liquefaction and piping of granular sediments (11337).

Data Availability Statement: No new data were created or analyzed in this study. Data sharing is not applicable to this article. All recalculated data are reported in the article.

Conflicts of Interest: The authors declare no conflict of interest.

\section{References}

1. Zuddas, P.; Mucci, A. Kinetics of calcite precipitation from seawater: I. A classical chemical kinetics description for strong electrolyte solutions. Geochem. Cosmochem. Acta 1994, 58, 4353-4362. [CrossRef]

2. Tai, C.Y.; Chang, M.C. Growth of calcite seeds in a magnetized environment. J. Cryst. Growth 2014, 389, 5-11. [CrossRef]

3. Chhim, N.; Kharbachi, C. Inhibition of calcium carbonate crystal growth by organic additives using the constant composition method in conditions of recirculating cooling circuits. J. Cryst. Growth 2017, 472, 35-45. [CrossRef]

4. Reddy, M.M.; Nancollas, G.H. The Crystallization of Calcium Carbonate 1. Isotopic Exchange and Kinetics. J. Colloid Interface Sci. 1971, 36, 166-172. [CrossRef]

5. Alamdari, A.; Alamdari, A.; Mowla, D. Kinetics of calcium carbonate precipitation through $\mathrm{CO}_{2}$ absorption from flue gas into distiller waste of soda ash plant. J. Ind. Eng. Chem. 2014, 20, 3480-3486. [CrossRef]

6. Van Paassen, L.A. Biogrout, Ground Improvement by Microbial Induced Carbonate Precipitation. Ph.D. Thesis, Delft University of Technology, Delft, The Netherlands, 2009.

7. Kim, D.H.; Mahabadi, N.; Jang, J.; van Paassen, L.A. Assessing the kinetics and pore-scale characteristics of biological calcium carbonate precipitation in porous media using a microfluidic chip experiment. Water Resour. Res. 2021, 56, e2019WR025420. [CrossRef]

8. Busenberg, E.; Plummer, L.N. A comparative study of the dissolution and crystal growth kinetics of calcite and aragonite. Stud. Diagenesis USGS Bull. 1986, 1578, 139-168.

9. Plummer, L.N.; Busenberg, E. The solubilities of calcite, aragonite and vaterite in CO2-H2O solutions between 0 and $90 \mathrm{C}$, and an evaluation of the aqueous model for the system CaCO3-CO2-H2O. Geochim. Cosmochim. Acta 1982, 46, 1011-1040. [CrossRef]

10. Kaschiev, D.; Rosmalen, G.M. Review: Nucleation in solutions revisited. Cryst. Res. Technol. 2003, 38, 555-574. [CrossRef]

11. Parkhurst, D.L. User's Guide to PHREEQC: A Computer Program for Speciation, Reaction-Path, Advective-Transport and Inverse Geochemical Calculations; United States Geological Survey: Lakewood, CO, USA, 1995.

12. Ogino, T.; Suzuki, T.; Sawada, K. The formation and transformation mechanism of calcium carbonate in water. Geochem. Cosmochim. 1987, 51, 2757-2767. [CrossRef]

13. Davies, C.W.; Jones, A.L. The precipitation of silver chloride from aqueous solutions. Trans. Faraday Soc. 1955, 51, 812-817. [CrossRef]

14. De Yoreo, J.J.; Vekilov, P. Principles of crystal nucleation and growth. In Biomineralization; Reviews in Mineralogy and Geochemistry; Dove, P.M., de Yoreo, J.J., Eds.; Mineralogical Society of America: Washington, DC, USA, 2003; pp. 57-93.

15. Nancollas, G.H.; Reddy, M.M. The Crystallization of Calcium Carbonate 2. Calcite Growth Mechanism. J. Colloid Interface Sci. 1971, 37, 824-830. [CrossRef]

16. Mucci, A. Growth kinetics and composition of magnesian calcite overgrowths precipitated from seawater: Quantitative influence of orthophosphate ions. Geochim. Cosmochim. Acta 1986, 50, 2255-2265. [CrossRef]

17. Mucci, A.; Canuel, R.; Zhong, S. The solubility of calcite and aragonite in sulfate-free seawater and the seeded growth kinetics and composition of the precipitates at $25^{\circ} \mathrm{C}$. Chem. Geol. 1989, 74, 309-320. [CrossRef] 
18. Dromgoole, E.L.; Walter, L.M. Inhibition of calcite growth rates by $\mathrm{Mn}^{2=}$ in $\mathrm{CaCl}_{2}$ solutions at 10,25 , and 50 C. Geochim. Cosmochim. Acta 1990, 54, 2991-3000. [CrossRef]

19. Gutjahr, A.; Dabringhaus, H.; Lacmann, R. Studies of the growth and dissolution kinetics of the $\mathrm{CaCO}_{3}$ polymorphs calcite and aragonite I. Growth and dissolution rates in water. J. Cryst. Growth 1996, 158, 296-309. [CrossRef]

20. Gomez-Morales, J.; Torrent-Burgues, J. Precipitation of calcium carbonate from solutions with varying $\mathrm{Ca}^{2+} / \mathrm{carbonate}$ ratios. J. Cryst. Growth 1996, 166, 1020-1026. [CrossRef]

21. Kralj, D.; Brecivic, L. Vaterite growth and dissolution in aqueous solution III. Kinetics of transformation. J. Cryst. Growth 1997, 177, 248-257. [CrossRef]

22. Van der Weijden, R.D.; van der Heijden, A.E. The influence of total clacium and total carbonate on the growth rate of calcite. J. Cryst. Growth 1997, 171, 190-196. [CrossRef]

23. Zhang, Y.; Dawe, R. The kinetics of calcite precipitation. Appl. Geochem. 1998, 13, 177-184. [CrossRef]

24. Zuddas, P.; Mucci, A. Kinetics of calcite precipitaiton from seawater: II. The influence of the ionic strength. Geochim. Cosmochim. Acta 1998, 62, 757-766. [CrossRef]

25. Lebron, I.; Suarez, D.L. Calcite nucleation and precipitation kinetics as affected by dissolved organic matter at $25 \mathrm{C}$ and $\mathrm{pH}>7.5$. Geochem. Cosmochem. 1996, 60, 2765-2776. [CrossRef]

26. Nilsson, Ö.; Sternbeck, J. A mechanistic model for calcite crystal growth using surface speciation. Geochim. Cosmochim. Acta 1999, 63, 217-225. [CrossRef]

27. Parsiegla, K.I.; Katz, J.L. Calcite growth inhibition by copper(II) I. Effect of supersaturation. J. Cryst. Growth 1999, 200, 213-226. [CrossRef]

28. Van der Weijden, C.H.; van der Weijden, R.D. Calcite growth: Rate dependence on saturation, on ratios of dissolved calcium and (bi)carbonate and on their complexes. J. Cryst. Growth 2014, 394, 137-144. [CrossRef]

29. Zhu, G.; Li, H. Crystallization behavior and kinetics of calcium carbonate in highly alkaline and supersaturated system. J. Cryst. Growth 2015, 428, 16-23. [CrossRef]

30. Kralj, D.; Brecivic, L. Vaterite growth and dissolution in aqueous solution I. Kinetics of crystal growth. J. Cryst. Growth 1990, 104, 793-800. [CrossRef]

31. Spanos, N.; Koutsoukos, P.G. Kinetics of Precipitation of Calcium Carbonate in Alkaline pH at Constant Supersaturation. Spontaneous and Seeded Growth. J. Phys. Chem. B 1998, 102, 6679-6684. [CrossRef]

32. Olderoy, M.O.; Xie, M. Growth and Nucleation of Calcium Carbonate Vaterite Crystals in Presence of Alginate. Cryst. Growth Des. 2009, 9, 5176-5183. [CrossRef]

33. Andreassen, J.P.; Hounslow, M.J. Growth and Aggregation of Vaterite in Seeded-Batch Experiments. AIChE J. 2004, 50, 2772-2782. [CrossRef]

34. Wolthers, M.; Nehrke, G. Calcite growth kinetics: Modeling the effect of solution stoichiometry. Geochim. Cosmochim. Acta 2012, 77, 121-134. [CrossRef]

35. Andersson, M.P.; Dobberschütz, S. A Microkinetic Model of Calcite Step Growth. Angew. Chem. Int. Ed. 2016, 55, 11086-11090. [CrossRef]

36. Sand, K.K.; Tobler, D.J. Calcite Growth Kinetics: Dependence on Saturation Index, $\mathrm{Ca}^{2+}: \mathrm{CO}_{3}{ }^{2-}$ Acitvity Ratio, and Surface Atomic Structure. Cryst. Growth Des. 2016, 16, 3602-3612. [CrossRef]

37. Kavanagh, A.M.; Rayment, T. Inhibitor Effects on Calcite Growth at Low Supersaturations. J. Chem. Soc. Faraday Trans. 1990, 86, 965-972. [CrossRef]

38. Gomez-Morales, J.; Torrent-Burgues, J. Nucleation of calcium carbonate at different initial pH conditions. J. Cryst. Growth 1996, 169, 331-338. [CrossRef]

39. Lin, R.; Zhang, J.Y. Nucleation and growth kinetics in synthesizing nanometer calcite. J. Cryst. Growth 2002, 245, 309-320. [CrossRef]

40. Sugiura, Y.; Onuma, K. Growth dynamics of vaterite in relation to the physico-chemical properties of its precursor, amorphous calcium carbonate, in the $\mathrm{Ca}-\mathrm{CO}_{3}-\mathrm{PO}_{4}$ system. Am. Mineral. 2016, 101, 289-296. [CrossRef]

41. Lorens, R.B. Sr, Cd, Mn and Co distribution coefficients in calcite as a function of calcite precipitation rate. Geochim. Cosmochim. Acta 1981, 45, 553-561. [CrossRef]

42. Manoli, F.; Dalas, E. The effect of sodium alginate on the crystal growth of calcium carbonate. J. Mater. Sci. Mater. Med. 2002, 13, 155-158. [CrossRef]

43. Tai, C.Y.; Chang, M.C. Magnetic effects on crystal growth rate of calcite in a constant-composition environment. J. Cryst. Growth 2008, 310, 3690-3697. [CrossRef]

44. Vavouraki, A.I.; Putnis, C.V. An Atomic Force Microscopy study of the growth of calcite in the presence of sodium sulfate. Chem. Geol. 2008, 253, 243-251. [CrossRef]

45. Perdikouri, C.; Putnis, C.V. An Atomic Force Microscopy Study of the Growth of a Calcite Surface as a Function of Calcium/Total Carbonate Concentration Ratio in Solution at Constant Supersaturation. Cryst. Growth Des. 2009, 9, 4344-4350. [CrossRef]

46. Ruiz-Agudo, E.; Putnis, C.V. Specific effects of background electrolytes on the kinetics of step propagation during calcite growth. Geochim. Cosmochim. Acta 2011, 75, 3803-3814. [CrossRef]

47. Ruiz-Agudo, E.; Putnis, C.V. Effect of $\mathrm{pH}$ on calcite growth at constant $\mathrm{aCa}^{2+} / \mathrm{aCO}_{3}{ }^{2-}$ ratio and supersaturation. Geochim. Cosmochim. Acta 2011, 75, 284-296. [CrossRef] 
48. Gebrehiwet, T.A.; Reddem, G.D. The Effect of the $\mathrm{CO}_{3}{ }^{2-}$ to $\mathrm{Ca}^{2+}$ Ion activity ratio on calcite precipitation kinetics and Sr ${ }^{2+}$ partitioning. Geochem. Trans. 2012, 13, 1. [CrossRef]

49. Hong, M.; Teng, H.H. Implications of solution chemistry effects: Direction-specific restraints on the step kinetics of calcite growth. Geochim. Cosmochim. Acta 2014, 141, 228-239. [CrossRef]

50. Nielsen, M.R.; Sand, K.K. Inhibition of Calcite Growth: Combined Effects of $\mathrm{Mg}^{2+}$ and $\mathrm{SO}_{4}{ }^{2-}$. Cryst. Growth Des. 2016, 16, 6199-6207. [CrossRef]

51. Teng, H.H.; Dove, P.M. Kinetics of calcite growth: Surface processes and relationships to macroscopic rate laws. Geochim. Cosmochim. Acta 2000, 64, 2255-2266. [CrossRef]

52. Bracco, J.N.; Grantham, M.C. Calcite Growth Rates As a Function of Aqueous Calcium-to-Carbonate Ratio, Saturation Index, and Inhibitor Concentration: Insight into the Mechanism of Reaction and Poisoning by Strontium. Cryst. Growth Des. 2012, 12, 3540-3548. [CrossRef]

53. Nasser, W.N.; Al Salhi, F.H. Kinetics determination of calcium carbonate precipitation behavior by inline techniques. Powder Technol. 2015, 270, 548-560. [CrossRef]

54. Mucci, A.; Morse, J.W. The incorporation of $\mathrm{Mg}^{2+}$ and $\mathrm{Sr}^{2+}$ into calcite overgrowths: Influences of growth rate and solution composition. Geochim. Cosmochim. Acta 1983, 47, 217-233. [CrossRef]

55. Verdoes, D.; Kashchiev, D. Determination of nucleation and growth rate froms induction times in seeded and unseeded precipitation of calcium carbonate. J. Cryst. Growth 1992, 118, 401-413. [CrossRef]

56. Waly, T.; Kennedy, M.D. On the induction time of $\mathrm{CaCO}_{3}$ : Effect of ionic strength. Desalination Water Treat. 2012, 39, 55-69. [CrossRef]

57. Söhnel, O.; Mullin, J.W. A method for the determination of precipitation induction periods. J. Cryst. Growth 1978, 44, 377-382. [CrossRef]

58. Söhnel, O.; Mullin, J.W. Precipitation of calcium carbonate. J. Cryst. Growth 1982, 60, 239-250. [CrossRef]

59. Liouliou, M.G.; Paraskeva, C.A. Heterogeneous nucleation and growth of calcium carbonate on calcite and quartz. J. Colloid Interface Sci. 2007, 308, 421-428. [CrossRef]

60. Flaten, E.M.; Seiersten, M. Induction time studies of calcium carbonate in ethylene glycol and water. Chem. Eng. Res. Des. 2010, 88, 1659-1668. [CrossRef]

61. He, S.; Kan, A.T. Inhibition of calcium carbonate precipitation in $\mathrm{NaCl}$ brines from 25 to $90{ }^{\circ} \mathrm{C}$. Appl. Geochem. 1999, $14,17-25$. [CrossRef]

62. Pochitalkina, I.A.; Kekin, P.A. Crystallization Kinetics of Calcium Carbonate at a Stoichiometric Ratio of Components. Russ. J. Phys. Chem. A 2016, 90, 2346-2351. [CrossRef]

63. Brecivic, L.; Nielsen, A.E. Solubility of amorphous calcium carbonate. J. Cryst. Growth 1989, 98, 504-510. [CrossRef]

64. Gebauer, D.; Cölfen, H. Prenucleation clusters and non-classical nucleation. Nano Today 2011, 6, 564-584. [CrossRef]

65. Cartwright, J.H.E.; Checa, A.G. Calcium carbonate polymorphism and its role in biomineralisation: How many ACCs are there? Angew. Chem. Int. Ed. 2012, 51, 11960-11970. [CrossRef] [PubMed]

66. Bots, P.; Benning, L.G. Mechanistic Insights into the Crystallization of Amorphous Calcium Carbonate (ACC). Cryst. Growth Des. 2012, 12, 3806-3814. [CrossRef]

67. Saharay, M.; Yazaydin, A.O. Dehydration-Induced Amorphous Phases of Calcium Carbonate. J. Phys. Chem. B 2013, 117, 3328-3336. [CrossRef] [PubMed] 